\title{
Geographical structure of gene diversity in Quercus petraea (Matt.) Liebl. II: Multilocus patterns of variation
}

\author{
A. KREMER* \& A. ZANETTO \\ INRA, Laboratoire de génétique et d'amélioration des arbres forestiers, BP 45, 33611 Gazinet Cedex, France
}

\begin{abstract}
Two-locus composite disequilibria were estimated for all 28 pairs of loci (from eight loci) in 81 populations of Quercus petraea spread over the natural distribution of the species. Significant disequilibria were found in almost all populations for two pairs (Aap-A/Lap-A, Mr-A/Dia-A) that have also shown strong linkage in cosegregation analysis. These pairs belong to the so-called complex loci producing nearly identical gene products and that are tightly linked. Significant disequilibria were also found for other pairs of loci that are linked to a smaller degree. The amount of disequilibrium followed a geographical pattern. The number of pairs showing significant disequilibria per population was higher on the edges of the natural range (Norway, Great Britain, Turkey). Disequilibria for the two pairs (Aap-A/Lap-A, Mr-A/Dia-A) were also higher at the edges of the distribution and were correlated with longitude. Population differentiation resulting from the associations of alleles at different loci was increased when the correlations of allele frequencies at the within- and between-population level were of different magnitude. It is suspected that correlations at the between-population level may arise from historical causes rather than gametic disequilibrium. Finally, the first canonical variate (multivariate score) including allelic frequencies of all eight loci follows a strong longitudinal pattern of variation.
\end{abstract}

Keywords: allozymes, differentiation, disequilibrium, Quercus petraea.

\section{Introduction}

In a previous paper the geographical distribution of allele frequencies has been investigated for sessile oak (Quercus petraea) on a range-wide scale in Europe (Zanetto \& Kremer, 1995). These results showed that sessile oak is a highly variable species characterized by a low population differentiation along a longitudinal gradient. Single-locus data provide only a narrow glance at the shape of diversity of organisms, which function as multilocus systems. Allelic associations at different loci may arise through a variety of causes that do not affect single loci such as epistatic selection or hitchhiking effects (Hedrick, 1985); they can also be enhanced by factors affecting single loci such as Wahlund effects (Nei \& Li, 1973; Feldman \& Christiansen, 1975) or genetic drift (Ohta 1982a,b). Of particular evolutionary interest is the decay of disequilibrium over generations in allogamous plants. However, for extremely long-lived species like oaks, it is likely that

*Correspondence. E-mail: antoine.kremer@pierroton.inra.fr equilibrium values are not yet attained. It is our objective in this second paper to extend the singlelocus analysis either to identify new causes of the geographical patterns of diversity or to corroborate previous results obtained at the single-locus level.

Because temperate forest trees are predominantly outcrossing species with large population sizes, gametic or zygotic disequilibria have been seldom studied (Muona, 1982). The lack of data also partly results from the large sample size required to detect disequilibrium (Brown, 1975). However, the few allozymic data available have shown that disequilibria are generally low in large panmictic populations formed by trees (Muona, 1982; Bousquet et al., 1987). But when multivariate techniques were used for describing the distribution of diversity, higher population differentiation was usually detected than with single-locus analysis (Merkle et al., 1988; Yang \& Yeh, 1993). Discrepancies among the experimental results obtained so far on forest trees could result largely from the fact that physical linkage between loci was unknown when gametic disequilibrium was investigated in natural populations, 
whereas data available from other outcrossed species indicated disequilibrium for pairs of tightly linked loci (Hedrick et al., 1978; Hedrick, 1985). In a few cases similar observations were made for forest trees (Epperson \& Allard, 1987, in Pinus contorta). We attempted in the case of oaks to estimate gametic disequilibrium for pairs of loci among which linkage is known in a range-wide collection of populations in order to depict geographical patterns of variation at the multilocus level.

Our approach consisted of: (i) estimating the amount of two-locus disequilibria existing in each of the 81 natural populations sampled throughout the natural distribution of $Q$. petraea; (ii) describing the geographical distribution of disequilibria; (iii) subdividing the disequilibria into a within- and betweenpopulation component; (iv) evaluating the consequences of disequilibria on population differentiation; and (v) analysing the geographical pattern of multilocus associations through canonical variates. Disequilibrium and differentiation were estimated at the zygotic level by using composite measures of disequilibrium (Weir, 1990) or differentiation (Kremer et al., 1996). Composite measures have to be used as coupling and repulsion heterozygotes can not be identified. These measures account for allelic associations at the zygotic level, including of course gametic associations. Because of their estimation at the zygotic level, they are higher than gametic disequilibrium or $F_{\mathrm{ST}}$ values, but they do not depend on Hardy-Weinberg equilibrium assumptions. Because multilocus differentiation may also arise from allelic associations at the population level, and not only at the individual level as detected by disequilibrium (Kremer et al., 1996), correlation between alleles was computed and compared both at the individual and population levels.

\section{Materials and methods}

\section{Plant material}

Eighty-one populations of Quercus petraea of putative native origin were sampled over the natural range of the species, from Ireland to Turkey and from the French Pyrenees to Norway (Fig. 1). The collection also comprises populations originating from various altitudes ranging from sea level (French Brittany) to $1300 \mathrm{~m}$ (Alps), although most of the populations came from altitudes between 100 and $450 \mathrm{~m}$; only six populations originated from altitudes higher than $450 \mathrm{~m}$. Geographical data were recorded for each population (latitude, longitude, altitude).

In each stand, acorns were collected from the ground over an area of 15-20 ha, representing about 50 collecting points equally distributed with 100-200 seeds for each point. Seeds were only harvested when the fruiting was above average (more than 50 per cent of the trees bearing acorns). Seeds from all collection points were bulked into a single lot. These seed lots were further used for the establishment of provenance tests. A random sample of 120 seeds for each population was taken for the study of allozyme

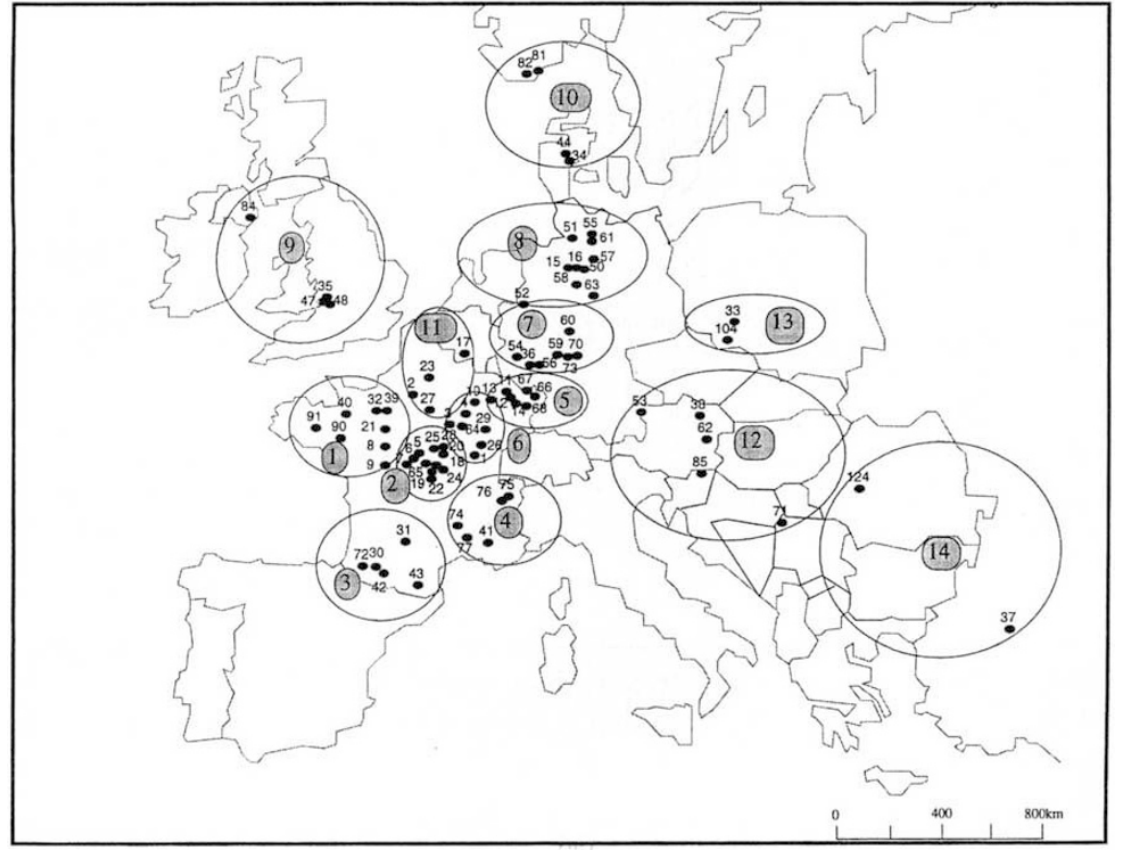

(C) The Genetical Society of Great Britain, Heredity, 78, 476-489.
Fig. 1 Geographical distribution of the populations of Quercus petraea. Populations were clustered in 14 groups according to their geographical proximities. 
variation. In a few cases when collections could be made on single trees, open-pollinated progenies were collected in a stand on the same area. Acorns were harvested from at least 10 trees per stand $(20$ acorns for each family) and a random subset of four to 12 seeds per family was subsequently used for electrophoresis.

\section{Starch ge/ electrophoresis}

Acorns were soaked in water for $24 \mathrm{~h}$ and germinated on vermiculite in an incubator. When the radicles were $2-4 \mathrm{~cm}$ long, enzymes were extracted from the radicle tissues and separated by standard horizontal starch gel electrophoresis. Formulations for extraction, electrode and gel buffers are given in Zanetto et al. (1994). Buffer formulations for enzymes stains were adapted from Cheliak et al. (1984), Conkle et al. (1982) and Vallejos (1983).

Eight enzymes were analysed for the multilocus analysis: acid phosphatase (ACP, EC 3.1.3.2), alanine aminopeptidase (AAP, EC 3.4.11.1), diaphorase (DIA, EC 1.8.1.4), glutamic-oxaloacetic transaminase (GOT, EC 2.6.1.1), leucine aminopeptidase (LAP, EC 3.4.11.1), menadione reductase (MR, EC 1.6.99.2), phosphoglucoisomerase (PGI,

Table 1 Distribution of zygotic disequilibrium and homogeneity tests for Quercus petraea

\begin{tabular}{|c|c|c|c|c|c|}
\hline Pairs of loci & $\begin{array}{c}\text { No. of populations } \\
\text { showing a } \\
\text { significant } \\
\text { disequilibrium }\end{array}$ & $\begin{array}{l}\text { Homogeneity } \\
\text { test among } \\
\text { populations }\end{array}$ & $\begin{array}{l}\text { Homogeneity } \\
\text { test among } \\
\text { regions }\end{array}$ & $\begin{array}{l}\text { Disequilibrium } \\
\text { in the } \\
\text { pooled data }\end{array}$ & $r$ \\
\hline$A a p-A / A c p-C$ & 14 & $* *$ & NS & NS & 0.09 \\
\hline Aap-A/Got-B & 5 & NS & NS & NS & $\mathrm{nl}$ \\
\hline Aap-A/Lap-A & 80 & $* *$ & $* *$ & $* *$ & $\begin{array}{c}0.00-0.16 \\
(0.00-0.06)\end{array}$ \\
\hline Aap-A/Mr-A & 3 & NS & NS & NS & \\
\hline Aap-A/Pgi-B & 9 & $* *$ & NS & NS & $(0.10-0.32)$ \\
\hline Aap-A/Pgm-A & 6 & $*$ & $* *$ & NS & $\mathrm{nl}$ \\
\hline Aap-A/Dia-A & 6 & * & NS & NS & $\mathrm{nl}$ \\
\hline$A c p-C / G o t-B$ & 2 & NS & * & NS & \\
\hline Acp-C/Lap- $A$ & 10 & $* *$ & NS & NS & 0.09 \\
\hline$A c p-C / M r-A$ & 12 & $* *$ & $* *$ & * & \\
\hline Acp-C/Pgi-B & 6 & NS & $*$ & NS & \\
\hline Acp-C/Pgm- $A$ & 5 & $* *$ & NS & NS & $\mathrm{nl}$ \\
\hline Acp-C/Dia-A & 10 & $* *$ & $*$ & NS & \\
\hline Got-B/Lap-A & 4 & NS & $*$ & NS & \\
\hline Got-B/Mr-A & 6 & $* *$ & $* *$ & $* *$ & $\mathrm{nl}$ \\
\hline Got-B/Pgi-B & 1 & NS & NS & NS & $\mathrm{nl}$ \\
\hline Got-B/Pgm-A & 4 & $*$ & NS & NS & $\mathrm{nl}$ \\
\hline Got-B/Dia-A & 2 & NS & NS & NS & \\
\hline Lap-A/Mr-A & 3 & NS & NS & NS & \\
\hline Lap-A/Pgi-B & 8 & $* *$ & NS & NS & $\begin{array}{c}0.00 \\
(0.10-0.11)\end{array}$ \\
\hline Lap-A/Pgm-A & 8 & $* *$ & $* *$ & NS & $\mathrm{nl}$ \\
\hline Lap-A/Dia-A & 8 & $* *$ & NS & NS & \\
\hline$M r-A / P g i-B$ & 5 & NS & NS & NS & \\
\hline$M r-A / P g m-A$ & 9 & $*$ & $* *$ & NS & $\mathrm{nl}$ \\
\hline$M r-A / D i a-A$ & 68 & $* *$ & $* *$ & $* *$ & $(0.10-0.22)$ \\
\hline Pgi-B/Pgm-A & 7 & $*$ & $* *$ & NS & 0.33 \\
\hline Pgi-B/Dia-A & 8 & * & NS & NS & \\
\hline Pgm-A/Dia-A & 6 & * & $* *$ & NS & \\
\hline
\end{tabular}

$r$, recombination frequency in the controlled crosses (Müller-Starck et al., 1996) (values within brackets have been calculated for Quercus robur, Zanetto et al., 1995) (missing data for $r$ indicate that recombination frequencies could not be calculated because no informative crosses were available).

$\mathrm{nl}$, no significant linkage in $Q$. petraea or $Q$. robur.

${ }^{*} P<0.05,{ }^{*} P<0.01 ;$ NS, not significant. 
EC 5.3.1.9) and phosphoglucomutase (PGM, EC 5.4.2.2). Segregation analysis (Müller-Starck et al., 1996; Zanetto et al., 1996) showed that these enzymes were encoded by eight loci $(A c p-C, A a p-A$, Dia- $A$, Got-B, Lap-A, Mr-A, Pgi-B, Pgm- $A$ ) among which linkage has been detected (Table 1). Because full-sib families were not available to analyse linkage in all the 28 pairs of loci in Quercus petraea (MüllerStarck et al., 1996), we added the linkage data available in Quercus robur (Zanetto et al., 1996). It has been shown that these two species are closely related and share all alleles including the rare alleles (Zanetto et al., 1994), and that linkage groups are similar in the two species (Müller-Starck et al., 1996; Zanetto et al., 1996). Hence linkage detected in $Q$. robur may be used to interpret disequilibrium in $Q$. petraea. However, even when data were combined across the two species, linkage relationships were only available for 16 of the 28 pairs of loci.

\section{Disequilibrium in a single population}

Genotypic disequilibria were estimated for all pairwise combinations of loci in all 81 populations following the method of Weir $(1979,1990)$. The calculations were performed for diallelic loci, i.e. the most frequent alleles in one class and all other alleles bulked in the other class.

An unbiased estimate of Burrows's composite measure of linkage disequilibrium is given by (Cockerham \& Weir, 1977; Black \& Krafsur, 1985):

$$
\Delta_{i j}=(N /(N-1)) \times\left(\left(T_{i j} / N\right)-2 p_{i} p_{j}\right)
$$

where $N$ is the number of individuals sampled in the population, $T_{i j}$ is the number of times an allele $i$ at one locus appears with another allele $j$ at the second locus in the same individual, and $p_{i}$ is the frequency of allele $i$ in the population.

The use of a composite measure of disequilibrium is recommended on genotypic data where it is not possible to distinguish coupling and replusion heterozygotes (Laurie-Ahlberg \& Weir, 1979; Weir, 1990). Heterogeneity of disequilibria among populations and regions was tested by converting $\Delta_{i j}$ into correlation coefficients (Fisher's $z$-transformation) and partitioning the total $\chi^{2}$ into region and population components (Weir, 1990, p. 112). Calculations of $\Delta_{i j}$ were obtained from the package LD79 (Weir, 1990 ) adapted to the case of multiple populations.

\section{Disequilibrium in subdivided populations}

Zygotic disequilibria over the set of 81 populations were subdivided into within- and between-popula- tions components according to the method given by Ohta (1982a,b), similar to Nei's subdivision of the total diversity into the same components. The method was developed to distinguish between the different evolutionary forces that may generate disequilibria. A series of five different components was calculated and compared (Ohta, 1982a): $D_{\mathrm{IS}}^{2}$ and $D_{\text {IS }}^{\prime 2}$ are within-subpopulation components, $D_{\mathrm{ST}}^{2 \mathrm{~T}}$ and $D_{\text {ST }}^{\prime 2}$ are among-populations components and $D_{\mathrm{IT}}^{2}$ is the total population component of disequibria.

Analytical calculations have shown that when migration is limited among subpopulations, e.g. when disequilibria are created mainly by genetic drift, then $D_{\mathrm{IS}}^{2}$ is less than $D_{\mathrm{ST}}^{2}$ and $D_{\mathrm{IS}}^{\prime 2}$ is greater than $D_{\mathrm{ST}}^{\prime 2}$ (Ohta, 1982b). On the other hand, if systematic effects contribute to maintain allelic associations in the different populations then $D_{\mathrm{IS}}^{2}$ is greater than $D_{\mathrm{ST}}^{2}$ and $D_{\mathrm{iS}}^{\prime 2}$ is less than $D_{\mathrm{ST}}^{\prime 2}$. The comparison of the values of the different components allows therefore a distinction between stochastic and systematic causes of gametic disequilibria. The calculations of the different components were made according to Black \& Krafsur (1985) adapted to the diallelic case.

It is worth noting that $D_{\text {IS }}^{\prime 2}$ is a betweenpopulation component, although it has been given by Ohta (1982a) the subscript IS. $D_{\text {IS }}^{\prime 2}$ represents the variance among subpopulations of the observed allelic associations. In a hierachical sampling scheme as in our case (region + population) $D_{\text {is }}^{\prime 2}$ can be subdivided into two components, (i) one arising from the variation of allelic associations among regions $D_{\mathrm{IR}}^{\prime 2}$ and (ii) one arising from the variation of observed allelic associations among populations (within regions) $D_{\mathrm{RS}}^{\prime 2}$.

$D_{\mathrm{R}}^{\prime 2}=\sum_{r}\left\{\sum_{i} \sum_{j}\left(T_{i j, r}-\bar{T}_{i j}\right)^{2}\right\} / R$

where $T_{i j, r}$ is the frequency with which $i$ and $j$ appear together in individuals averaged over all populations in region $r$, and $R$ is the number of regions.

$D_{\mathrm{RS}}^{\prime 2}=\sum_{r} \sum_{l}\left\{\sum_{i} \sum_{j}\left(T_{i j, l}-T_{i j, r}\right)^{2}\right\} / L$.

As a result the subdivision of the variance of disequilibria over all populations becomes (Ohta, 1982a):

$D_{\mathrm{IT}}^{2}=D_{\mathrm{ST}}^{\prime 2}+D_{\mathrm{IR}}^{\prime 2}+D_{\mathrm{RS}}^{\prime 2}$ 


\section{Multilocus differentiation}

Levels of differentiation arising from allelic associations at different loci were calculated using the multilocus approach developed by Kremer et al. (1996) derived from Long et al. (1987). This method extends the ANOVA approach of Weir \& Cockerham (1984) where the expression of a given allele $\left(X_{i j}\right)$ of individual $j$ belonging to population $i$ can be subdivided into:

$X_{i j}=\mu+P_{i}+I_{i j}$

where $P_{i}$ is the effect attributable to population $i$ and $I_{i j}$ is the effect attributable to individual $j$. For a locus having two alleles, there is only one variable analysed with model (5): $X_{i j}$ is equal to 1 , if indiviual $i j$ is a homozygote and bearing that allele, $X_{i j}$ is equal to 0.5 if individual $i j$ is a heterozygote and $X_{i j}$ is equal to 0 if individual $i j$ is a homozygote and bearing the alternative allele. If there are multiple alleles at a given locus, and for different loci, model (5) can easily be extended to the multivariate case by replacing $X_{i j}$ by a vector $\mathbf{x}$ comprising $A-L$ elements $(A$ being the total number of alleles over all loci and $L$ the number of loci). In terms of variances model (5) can now be written as:

$\mathbf{X}=\mathbf{P}+\mathbf{I}$

where $\mathbf{X}, \mathbf{P}$ and $\mathbf{I}$ are the variance-covariance matrices corresponding to the total, population and individual effects.

A composite multilocus differentiation measure $C F_{\text {sT }}$ (Kremer et al., 1996) can be calculated from model (6):

$C F_{\mathrm{STm}}=\lambda_{\max }\left[\mathbf{C F}_{\mathrm{ST}}\right]$

where $\mathbf{C F}_{\mathrm{ST}}=\left[\mathbf{X}^{-1 / 2} \mathbf{P} \mathbf{X}^{-1 / 2}\right]$.

$\lambda_{\max }$ is the largest eigenvalue of matrix [CF $\mathbf{C F}_{\mathrm{ST}}$ ]. It has been shown that $C F_{\mathrm{STm}}$ is a composite measure of differentiation that accounts for allelic associations at the zygotic level when coupling and repulsion heterozygotes cannot be separated (Kremer et al., 1996). Because $C F_{\text {STm }}$ accounts for allelic associations at the zygotic level and not at the gametic level, it is always higher than $F_{\mathrm{ST}}$.

When a given combination of loci is considered, $C F_{\text {STm }}$ may be compared with differentiation values if disequilibria were nonexistent, i.e. differentiation of the locus having the largest single-locus differentiation $C F_{\text {ST max. }}$

Additional causes of multilocus differentiation may arise from allelic associations detected at the individual level (zygotic disequilibria, matrix I) and/or associations detected at the population level (matrix P), i.e. correlation among allelic frequencies. Therefore correlation coefficients at both levels $\left(r_{\mathrm{w}}\right.$, correlation within populations and $r_{\mathrm{b}}$, correlation between populations) were computed from model (5):

$$
\begin{aligned}
& r_{\mathrm{w}}=\operatorname{Cov}\left(I k, I k^{\prime}\right) / \sigma_{l k} \sigma_{l k^{\prime}} \\
& r_{\mathrm{b}}=\operatorname{Cov}\left(P k, P k^{\prime}\right) / \sigma_{P k} \sigma_{P k^{\prime}}
\end{aligned}
$$

where $I k$ and $P k$ are the $I_{i j}$ and $P_{i}$ values for allele $k$ of model (5), and $\sigma_{l k}$ and $\sigma_{P k}$ the corresponding standard deviations. These correlations were calculated between the most frequent alleles at the two loci.

Finally, canonical variates $z$ corresponding to the largest differentiation were computed from (6) for each population.

$z=\mathbf{x}^{\prime} \mathbf{u}$

where $\mathbf{x}^{\prime}$ is the transpose of the vector of the original data and $\mathbf{u}$ is the eigenvector with the largest differentiation $\left(C F_{\mathrm{sTm}}\right)$ of matrix $\mathbf{C F}_{\mathrm{sr}}$.

\section{Results}

\section{Zygotic disequilibria in single populations}

Composite zygotic disequilibria were calculated in the 81 populations for all 28 two-locus combinations (Table 1). Each of the 28 combinations showed at least in one population a significant disequilibrium, and each population showed at least for one twolocus combination a significant disequilibrium. A general picture of the distribution of the disequilibria among populations and among loci combinations can be given by a two-way table ( 81 populations in rows and 28 locus combinations in columns). Marginal counts of the significant disequilibria in this two-way table indicate that they were unevenly distributed among populations and among pairs of loci. However, there was more heterogeneity of disequilibria among pairs of loci than among populations (Table 1). The distribution of the marginal counts on the rows (population) shows a normal type curve whereas the distribution of marginal column counts (two-locus combination) shows a skewed distribution.

The number of significant disequilibria for a given two-locus combination varied between 1 (Got-B/ $P g i-B)$ and 80 (Aap-A/Lap-A) (Table 1). Nineteen combinations revealed significant heterogeneity among populations. The two-locus combinations that exhibited the largest disequilibria are those involving tightly linked loci. This is particularly the case for Aap-A and Lap-A and for Mr-A and Dia-A. These 
two combinations show significant disequilibria in almost all populations. The $\Delta_{i j}$ are always positive for the Aap-A/Lap-A combinations, indicating that the alleles that are preferentially associated in genotypes are the same in all populations (Fig. 2a). In the case of the $M r-A / D i a-A$ combination, the significant values of $\Delta_{i j}$ are also positive revealing a preferential association of alleles over the population sample (Fig. 2b). Other pairs of loci, for which significant disequilibria were found, correspond generally to those where linkage was observed in cosegregation studies (Müller-Starck et al., 1996; Zanetto et al., 1996) (Aap-A|Acp-C, Acp-C/Lap-A, Aap-Al Pgi-B).

The number of significant disequilibria for a given population varied between 1 and 9. Populations 8 and 52 (Fig. 1) were among those that expressed only one significant disequilibrium for the Aap-A/

(a)

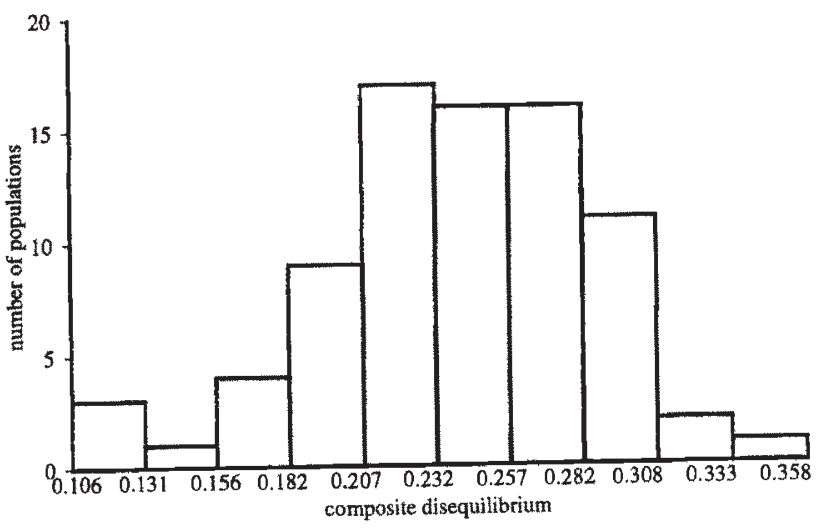

(b)



Fig. 2 (a) Distribution of the composite zygotic disequilibrium (Aap-A/Lap-A) and (b) distribution of the composite zygotic disequilibrium ( $M r-A / D i a-A)$ for Quercus petraea.
Lap- $A$ combination, whereas populations 29 and 81 had the largest number of disequilibria ( 7 and 9 ).

\section{Geographical distribution of disequilibria}

The geographical distribution of disequilibria was analysed for three different variables: the $\Delta_{i j}$ values for the two-locus associations that have a tendency to show disequilibria (Aap-A/Lap-A and Dia-A/ $M r-A)$ and the number of significant disequilibria per population. The analysis was conducted in two complementary ways: (i) by calculating the correlation between significant $\Delta_{i j}$ values and geographical data (longitude, latitude, altitude); and (ii) by testing for regional differences among significant $\Delta_{i j}$ values averaged within each region with a classical ANOVA.

Among the three variables, the two $\Delta_{i j}$ values showed significant correlations with longitude, although the signs of the correlations were different (Table 2). For Aap- $A /$ Lap- $A$ the largest disequilibria appeared in the eastern part of the natural range, whereas for $D i a-A / M r-A$ the largest disequilibria were present in the western part of the range. For example, when comparing regions 1 and $12, \Delta_{i j}$ mean values were, respectively, 0.206 and 0.270 for Aap-A/Lap- $A$ and 0.072 and 0.034 for Dia-A/Mr-A. There were no significant correlations between the $\Delta_{i j}$ values and latitude or altitude.

The mean number of significant disequilibria within a population varied between 2.82 (region 2) and 5.25 (region 9) (Fig. 3). There was no significant correlation between geographical data and the number of disequilibria per population, although a systematic trend of variation is suggested by the higher number of disequilibria in populations located on the edges of the distribution. Regions that showed the largest number of disequilibria were $9,7,14$ and 10 ; those showing the lowest were 1,2 , 5 and 4.

This trend is reinforced when global comparisons with all the three variables are made. For example, the British populations (region 9) exhibit the largest mean disequilibria for $D i a-A / M r-A(0.109)$ and the highest number of disequilibria per population (5.25). Region 14 exhibits the largest disequilibria for Aap-A/Lap-A $(0.278)$ and among the highest number of disequilibria $(5.00)$.

\section{Subdivision of disequilibria}

The variance of the 28 two-locus disequilibria was subdivided into a between- and a within-population component according to eqn (4) (Table 3). The apportionment of the variation attributable to these 
Table 2 Correlations between disequilibrium statistics and geographical data for Quercus petraea

\begin{tabular}{lrrrc}
\hline & Latitude & Longitude & Altitude & $F$-test \\
\hline $\begin{array}{l}\text { Composite disequilibrium } \\
\text { Aap- } A / \text { Lap- } A\end{array}$ & 0.218 & $0.244^{*}$ & -0.071 & $1.21(P=29 \%)$ \\
$\begin{array}{l}\text { Composite disequilibrium } \\
\text { Mr-A/Dia-A }\end{array}$ & -0.095 & $-0.290^{*}$ & -0.021 & $2.44(P=0.9 \%)$ \\
No. of disequilibria & 0.107 & 0.139 & 0.009 & $1.52(P=13 \%)$ \\
\hline
\end{tabular}

${ }^{*} P<0.05$.

$F$-test: differences among regions tested with ANOVA.

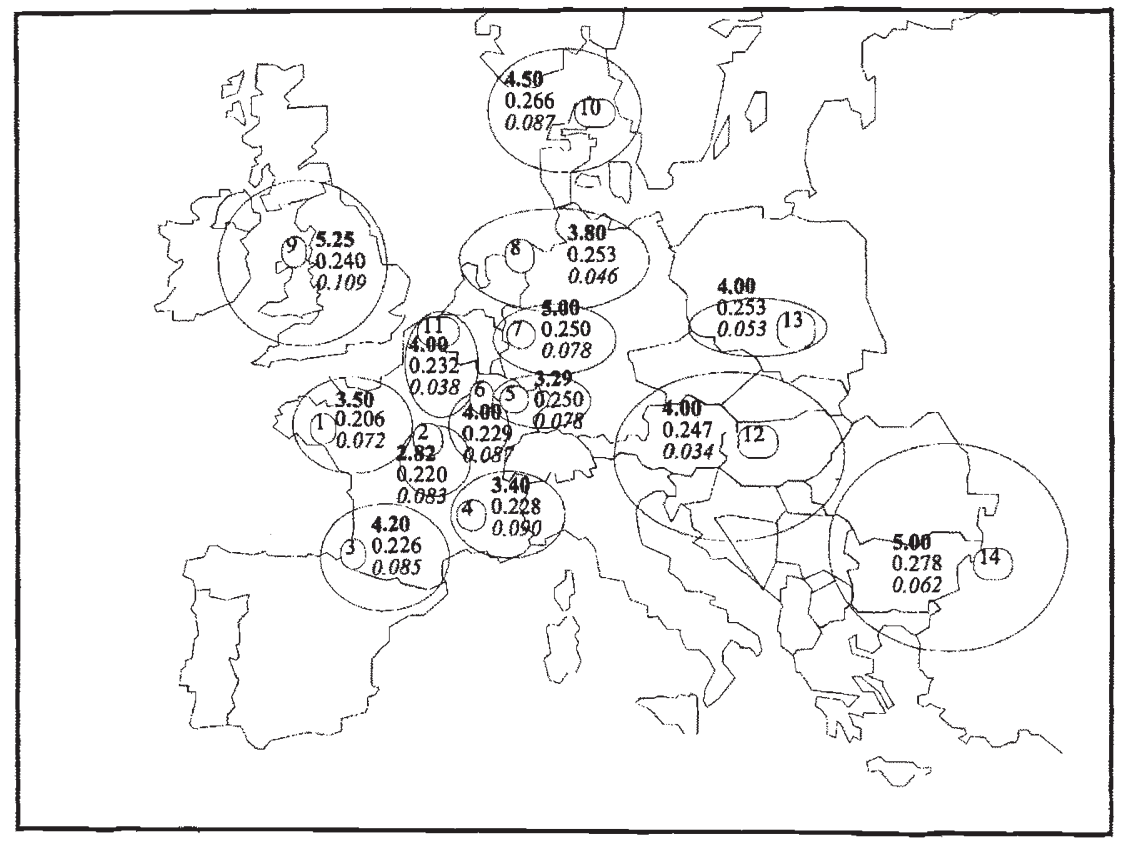

Fig. 3 Mean values of disequilibria in the different geographical regions of Quercus petraea. Bold characters indicate the mean number of significant disequilibria $(P<0.05)$ per population. Numbers in italic indicate the mean composite zygotic disequilibrium for $M r-A / D i a-A$. Numbers in roman characters indicate the mean composite disequilibrium for $A a p-A / L a p-A$. components varies according to the different two-locus combinations. There is a clear discrepancy between two categories of combinations.

(1) Combinations Aap-A/Lap-A and Dia-A/Mr-A are characterized by higher $D_{\mathrm{IS}}^{2}$ values than $D_{\mathrm{ST}}^{2}$ and for Aap-A/Lap- $A$ lower $D_{\mathrm{IS}}^{\prime 2}$ values than $D_{\mathrm{ST}}^{\prime 2}$. Variations of the disequilibria resulting from the subdivision into populations therefore explained only a minor part of the total disequilibrium in the total population. A further subdivison of $D_{\mathrm{IS}}^{\prime 2}$ into a regional and a population (within region) component for these two combinations shows that the regional component $\left(D_{\mathrm{IR}}^{\prime 2}\right)$ explains from 24 to 35 per cent of $D_{\text {is }}^{\prime 2}$ (Table 4).

(2) The data for the remaining locus combinations indicate that the variance of the expected allelic associations among populations $\left(D_{\mathrm{ST}}^{2}\right)$ or of the observed allelic associations among populations
$\left(D_{\mathrm{IS}}^{\prime 2}\right)$ are larger than the variances of disequilibrium within the populations $\left(D_{\mathrm{IS}}^{2}\right)$ or within the overall population $\left(D_{\mathrm{ST}}^{\prime 2}\right)$. These results are not caused by the lower number of populations showing significant disequilibria for these combinations (Table 1). When the components of disequilibria were only computed on the subset of populations showing significant disequilibria, similar results were obtained.

\section{Multilocus differentiation caused by disequilibria}

Multilocus differentiation may be caused by allelic associations either at the within- or at the betweenpopulation level. The within-populations component is given by the zygotic disequilibria, or by the correlation at the individual level $\left(\Delta_{i j}\right.$ in eqn $1, r_{\mathrm{w}}$ in eqn 8 ) whereas the among-populations component is given by the correlation at the population level $\left(r_{\mathrm{b}}\right.$ in eqn 9). Although there is a good correspondence 
Table 3 Ohta's components of zygotic disequilibria for Quercus petraea

\begin{tabular}{|c|c|c|c|}
\hline Loci & $\frac{D_{\mathrm{IS}}^{2}}{D_{\mathrm{ST}}^{2}}$ & $\frac{D_{\mathrm{ST}}^{\prime 2}}{D_{\mathrm{IS}}^{\prime 2}}$ & $\frac{D_{\mathrm{ST}}^{\prime 2}}{D_{\mathrm{IT}}^{2}}$ \\
\hline$A a p-A \mid A c p-C$ & 0.2458 & 0.0001 & 0.0001 \\
\hline Aap- $A / G o t-B$ & 0.0529 & 0.0000 & 0.0000 \\
\hline Aap- $A / L a p-A$ & 10.8969 & 3.1236 & 0.7575 \\
\hline Aap-AMr-A & 0.1193 & 0.0053 & 0.0052 \\
\hline Aap-A/Pgi-B & 0.1554 & 0.0008 & 0.0008 \\
\hline Aap-A/Pgm-A & 0.0956 & 0.0004 & 0.0004 \\
\hline Aap-A/Dia-A & 0.2500 & 0.0021 & 0.0021 \\
\hline$A c p-C / G o t-B$ & 0.0333 & 0.0009 & 0.0009 \\
\hline$A c p-C / L a p-A$ & 0.1782 & 0.0003 & 0.0003 \\
\hline Acp-C/Mr-A & 0.1595 & 0.0012 & 0.0012 \\
\hline$A c p-C / P g i-B$ & 0.0941 & 0.0000 & 0.0000 \\
\hline$A c p-C / P g m-A$ & 0.1050 & 0.0011 & 0.0011 \\
\hline Acp-C/Dia-A & 0.2326 & 0.0007 & 0.0007 \\
\hline Got-B/Lap-A & 0.0408 & 0.0001 & 0.0001 \\
\hline Got-B/Mr-A & 0.0762 & 0.0014 & 0.0014 \\
\hline Got-B/Pgi-B & 0.0368 & 0.0000 & 0.0000 \\
\hline Got-B/Pgm- $A$ & 0.0394 & 0.0000 & 0.0000 \\
\hline Got-B/Dia-A & 0.0652 & 0.0004 & 0.0004 \\
\hline Lap-A/Mr-A & 0.0933 & 0.0049 & 0.0049 \\
\hline Lap-A/Pgi-B & 0.1306 & 0.0007 & 0.0007 \\
\hline Lap-A/Pgm- $A$ & 0.0732 & 0.0005 & 0.0005 \\
\hline Lap-A/Dia-A & 0.2500 & 0.0052 & 0.0051 \\
\hline$M r-A / P g i-B$ & 0.0847 & 0.0000 & 0.0000 \\
\hline$M r-A / P g m-A$ & 0.0726 & 0.0006 & 0.0006 \\
\hline$M r-A / D i a-A$ & 2.1180 & 0.5166 & 0.3406 \\
\hline$P g i-B / P g m-A$ & 0.0971 & 0.0000 & 0.0000 \\
\hline Pgi-B/Dia-A & 0.1364 & 0.0000 & 0.0000 \\
\hline Pgm-A/Dia-A & 0.0890 & 0.0005 & 0.0005 \\
\hline Mean & 0.5722 & 0.1310 & 0.0406 \\
\hline
\end{tabular}

$D_{\text {IS }}^{2}=$ variance of the zygotic disequilibrium over all populations; $D_{\mathrm{IS}}^{\prime 2}=$ variance of the observed frequency that alleles $i$ and $j$ appear together in the same individual; $D_{\mathrm{ST}}^{2}=$ variance of the expected frequency that allele $i$ and $j$ are associated in the same individual; $D_{\mathrm{ST}}^{\prime 2}=$ sum (over all combination of alleles) of the disequilibria for the whole population; $D_{\mathrm{IT}}^{2}=$ total variance of disequilibrium.

between $r_{\mathrm{w}}$ values in Table 5 and the disequilibria data in Table 1 , there is an important discrepancy between $r_{\mathrm{w}}$ and $r_{\mathrm{b}}$ values in Table 5. For most two-locus associations, the data clearly show that associations among alleles at different loci are stronger at the between-population level than at the within-population level. The discrepancy between $r_{\mathrm{w}}$ and $r_{\mathrm{b}}$ has a strong effect on the level of multilocus differentiation.

Multilocus differentiation values are always higher than the maximum differentiation for a single locus, as expected (Table 5). The increase in differentiation amounts in some cases to 26 per cent (Aap-A)
$M r-A), 23$ per cent $($ Aap-A/Dia-A) or 22 per cent $(M r-A / D i a-A)$. These combinations correspond to the cases where the largest discrepancy exists between the within $\left(r_{\mathrm{w}}\right)$ and between $\left(r_{\mathrm{b}}\right)$ population correlations. On the other hand, when correlations were weak at both the within- and between-populations levels (for example Aap-A/Acp-C,Acp-C/Lap-A or $M r-A / P g m-A)$, the multilocus differentiation was of the same amount as the single-locus differentiation. Finally, when both correlations were of the same amount as for Aap-A/Lap-A, the multilocus differentiation is only slightly higher than the singlelocus differentiation. 
Table 4 Regional and population components of zygotic disequilibria for Quercus petraea

\begin{tabular}{lccccc}
\hline $\begin{array}{l}\text { Locus } \\
\text { combinations }\end{array}$ & $D_{\mathrm{IT}}^{2}$ & $D_{\mathrm{ST}}^{\prime 2}$ & $D_{\mathrm{l}}^{\prime 2}$ & $D_{\mathrm{RS}}^{\prime 2}$ & $D_{\mathrm{iS}}^{\prime 2}$ \\
\hline Aap-A/Lap-A & 0.343 & 0.264 & 0.028 & 0.051 & 0.079 \\
Mr-A/Dia-A & 0.078 & 0.027 & 0.012 & 0.039 & 0.051 \\
\hline
\end{tabular}

$D_{\mathrm{IT}}^{2}=$ total variance of disequilibrium; $D_{\mathrm{ST}}^{\prime 2}=$ sum (over all combination of alleles) of the disequilibria for the whole population; $D_{\mathrm{R}}^{\prime 2}=$ variation of allelic associations among regions; $D_{\mathrm{RS}}^{\prime 2}=$ variation of observed allelic associations among populations (within regions); $D_{1 S}^{\prime 2}=$ variance of the observed frequency that alleles $i$ and $j$ appear together in the same individual.

\section{Multilocus geographical patterns of variation}

Canonical variates were calculated when the multivariate ANOVA was computed on all eight loci according to model (10). The analysis included 15 variates, corresponding to the 15 most frequent alleles over all loci when alleles with frequencies lower than 5 per cent are removed. The population values for the first two canonical variates are plotted in Fig. 4a. The values of the first variate showing the largest $C F_{\mathrm{STm}}$ were subdivided in four classes so that their corresponding populations are recognizable in Fig. 4b. The first canonical variate shows a clear longitudinal trend of variation. Populations located on the western side of a line joining Perpignan to Copenhagen show higher values than those located

Table 5 Multilocus composite differentiation and within $\left(r_{\mathrm{w}}\right)$ and between $\left(r_{\mathrm{b}}\right)$ populations correlations between allelic frequencies for Quercus petraea

\begin{tabular}{|c|c|c|c|c|c|}
\hline Loci & $C F_{\mathrm{STm}}$ & $C F_{\mathrm{ST} \max }$ & $\frac{C F_{\mathrm{STm}}-C F_{\mathrm{STmax}}}{C F_{\mathrm{ST} \max }}$ & $r_{\mathrm{w}}$ & $r_{\mathrm{b}}$ \\
\hline Aap-A|Acp-C & 0.065 & 0.061 & 0.07 & -0.007 & -0.014 \\
\hline Aap-A/Got-B & 0.061 & 0.061 & 0.00 & 0.012 & -0.259 \\
\hline Aap-A/Lap-A & 0.098 & 0.088 & 0.11 & 0.844 & 0.919 \\
\hline Aap-A/Mr-A & 0.077 & 0.061 & 0.26 & -0.024 & -0.443 \\
\hline Aap-A/Pgi-B & 0.068 & 0.061 & 0.11 & -0.012 & -0.197 \\
\hline Aap-A/Pgm-A & 0.074 & 0.062 & 0.19 & 0.005 & 0.113 \\
\hline Aap-A/Dia-A & 0.075 & 0.061 & 0.23 & -0.014 & -0.298 \\
\hline$A c p-C / G o t-B$ & 0.069 & 0.055 & 0.11 & 0.019 & 0.320 \\
\hline$A c p-C / L a p-A$ & 0.089 & 0.088 & 0.01 & -0.014 & 0.041 \\
\hline$A c p-C / M r-A$ & 0.065 & 0.055 & 0.18 & -0.033 & 0.047 \\
\hline$A c p-C / P g i-B$ & 0.063 & 0.058 & 0.09 & 0.004 & -0.077 \\
\hline Acp $-C / P g m-A$ & 0.063 & 0.062 & 0.02 & 0.023 & 0.109 \\
\hline$A c p-C / D i a-A$ & 0.063 & 0.055 & 0.15 & -0.007 & -0.138 \\
\hline Got-B/Lap- $A$ & 0.090 & 0.088 & 0.02 & 0.023 & -0.242 \\
\hline Got-B/Mr-A & 0.054 & 0.051 & 0.06 & 0.023 & 0.344 \\
\hline Got-B/Pgi-B & 0.061 & 0.058 & 0.05 & -0.009 & 0.275 \\
\hline Got-B/Pgm-A & 0.065 & 0.062 & 0.05 & 0.011 & 0.039 \\
\hline Got-B/Dia-A & 0.055 & 0.050 & 0.10 & 0.003 & 0.312 \\
\hline Lap-A/Mr-A & 0.106 & 0.088 & 0.20 & -0.024 & -0.445 \\
\hline Lap-A/Pgi-B & 0.096 & 0.088 & 0.09 & -0.004 & -0.287 \\
\hline Lap-A/Pgm-A & 0.094 & 0.088 & 0.06 & 0.014 & 0.058 \\
\hline Lap-A/Dia-A & 0.101 & 0.088 & 0.15 & -0.025 & -0.295 \\
\hline$M r-A / P g i-B$ & 0.065 & 0.058 & 0.12 & 0.017 & -0.257 \\
\hline$M r-A / P g m-A$ & 0.063 & 0.062 & 0.02 & 0.021 & -0.013 \\
\hline$M r-A / D i a-A$ & 0.062 & 0.051 & 0.22 & 0.371 & 0.603 \\
\hline$P g i-B / P g m-A$ & 0.064 & 0.062 & 0.03 & -0.014 & 0.104 \\
\hline Pgi-B/Dia-A & 0.066 & 0.058 & 0.14 & 0.018 & -0.369 \\
\hline$P g m-A / D i a-A$ & 0.068 & 0.062 & 0.08 & -0.005 & -0.274 \\
\hline
\end{tabular}

$C F_{\text {STm }}=$ maximum multilocus differentiation $\left(\lambda_{\max }\right)$ : eqn (7); $C F_{\text {STmax }}=$ maximum single-locus differentiation; $r_{\mathrm{w}}=$ withinpopulation correlations between allelic frequencies: eqn $(8) ; r_{\mathrm{b}}=$ between-population correlations between allelic frequencies: eqn (9). Correlations were calculated between the most frequent alleles for the two loci. 
(a)

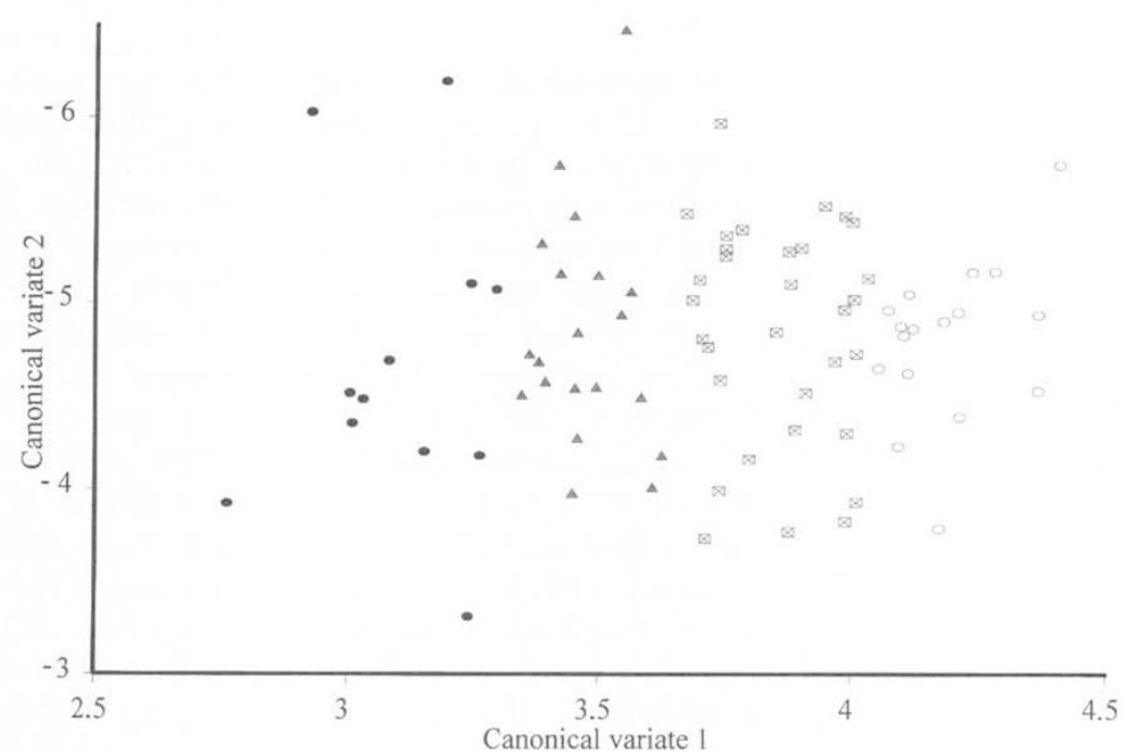

(b)

Fig. 4 (a) Graph of the first two canonical variate scores for the 81 populations of Quercus petraea. Plotted points were given different symbols according to the first canonical variate scores to localize the corresponding populations on the geographical map (Fig. 4b). (b) Geographical distribution of the first canonical variate scores. Symbols for points were assigned according to the ranking of the scores (see Fig. 4a).

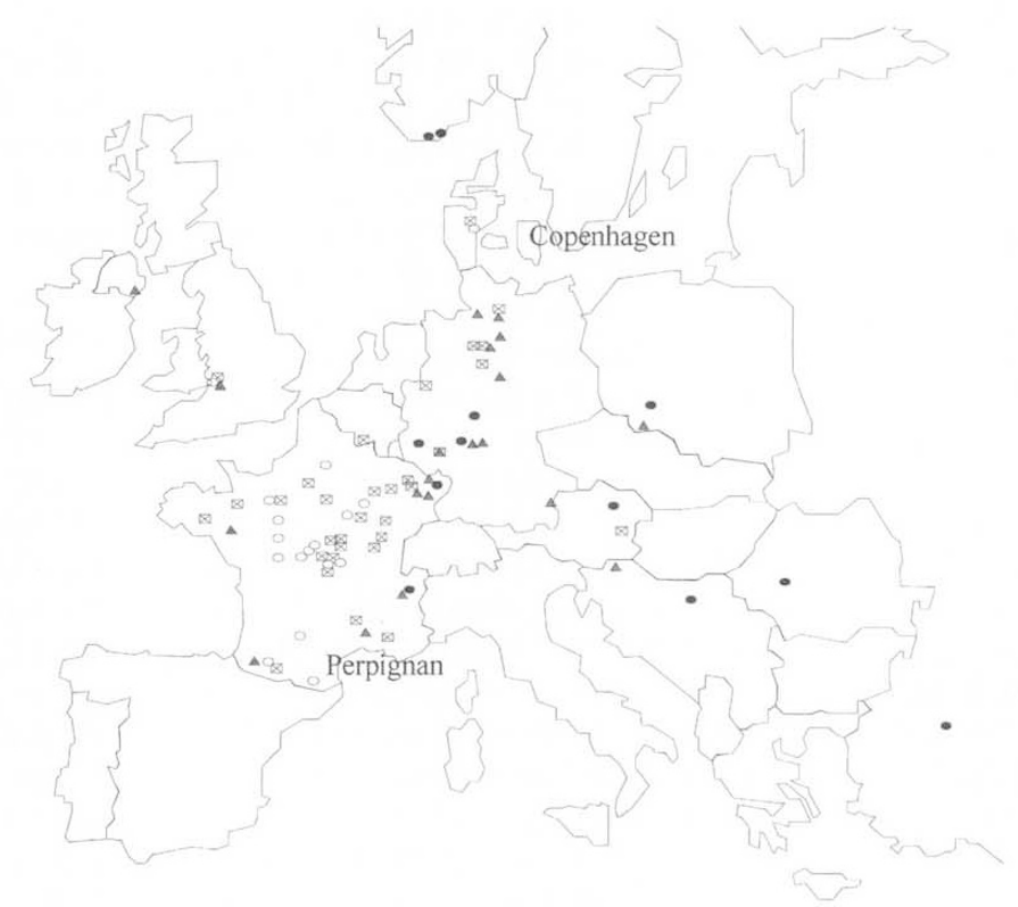

on the eastern side of that line with a few exceptions of populations located in Brittany or on the Pyrenees foothills. The longitudinal trend of variation was confirmed by the correlation between the first canonical variate and longitude $(r=-0.59$, $P<0.01)$. The first canonical variate is correlated (correlation at the between-population level) with the frequency of allele 4 of locus Aap- $A$ $(r=-0.693)$, allele 4 of locus Lap- $A(r=-0.768)$, allele 4 of locus $M r-A(r=-0.525)$. The differentiation among populations $\left(C F_{\mathrm{STm}}\right)$ for the first canonical variate amounts to 12.2 per cent.

(c) The Genetical Society of Great Britain, Heredity, 78, 476-489. 


\section{Discussion}

\section{Levels of two-locus disequilibria}

Among the 28 pairs of loci considered, all showed significant disequilibria in at least one population. However, only six pairs exhibited disequilibria in at least 10 populations; these pairs corresponded in general to tightly linked loci. The amount of zygotic disequilibria in $Q$. petraea is larger than generally reported for other forest tree species (Bousquet $e t$ al., 1987, in Alnus crispa; Yeh \& Morgan, 1987, in Pseudotsuga menziesii; Brown et al., 1975, in Eucalyptus obliqua). However, straightforward comparisons may be misleading as no data were available on physical linkage in these three species. Furthermore, Roberds \& Brotschol (1985) reported that extensive levels of disequilibria can be found in the seedling stage of Liriodendron tulipifera, whereas at a mature stage disequilibrium may disappear. The age variation of disequilibrium may be related to the concomitant decrease in homozygosity that has been reported in forest trees. Partial selfing generates an excess of associations of multiple homozygotes (Bennet \& Binet, 1956), which will be selected against during the development and closure of the stand. The oak results reported here were obtained from seed data, at a stage where selfed progeny may still exist, despite the strong allogamy of $Q$. petraea (Bacilieri et al., 1996). Tight linkage is of course a main cause of disequilibria, particularly for the two pairs Aap-A/Lap-A and Mr-A/Dia-A that exhibit in almost all populations significant allelic associations (Table 1), as shown also in Pinus contorta ssp. latifolia (Epperson \& Allard, 1987). But because oaks have large population sizes and are predominantly outcrossing species, the decay of the disequilibrium should be rather fast (Strauss et al., 1992). The maintenance of high levels of disequilibria for the two pairs of loci (Aap-A/Lap-A and $M r-A / D i a-A)$ can only be attributed to systematic forces as shown by the results of Ohta's subdivision of disequilibrium (Tables 3 and 4). If allelic associations are maintained across populations as a result of systematic effects then the variance of disequilibrium in the total population should be much larger than the variance of allelic associations in individuals within populations $\left(D_{\mathrm{ST}}^{\prime 2}>D_{\mathrm{IS}}^{\prime 2}\right)$, as shown by our data in Tables 3 and 4 . Even in the case of tight linkage, random causes such as genetic drift will result in negligible values of $D_{\mathrm{ST}}^{\prime 2}$ (Ohta, 1982b). Systematic causes may also be advocated to interpret the predominantly constant sign of the disequilibrium for the two pairs of loci across populations (Figs $2 a, b)$. These systematic causes are more likely to be functional than genetical. Indeed enzymes coded by the two pairs of loci that show strong disequilibria are involved in the same biochemical pathways. Both leucine aminopeptidase (LAP) and alanine aminopeptidase (AAP) hydrolyze peptide linkages adjacent to the free $\alpha$-amino groups of a peptide (Scandalios, 1969). Significant disequilibria for this functionally related pair of loci have also been reported in other organisms (Mitton \& Koehn, 1973, in mussels). In maize (Ott \& Scandalios, 1978), Aap- $A$ and Lap- $A$ are also tightly linked, but no data are available on gametic disequilibrium in natural populations in this species. On the other hand, diaphorase (DIA) and menadione reductase (MR) are two oxidoreductases involved in the shikimate pathway (Haslam, 1974). The two enzymes occupy successive steps in the biosynthesis of the quinones (Dixon \& Welb, 1979).

The zygotic disequilibria detected for the two pairs of loci (Aap-A/Lap-A and $M r-A / D i a-A$ ) appear therefore as examples of a rather general situation encountered in other species, where complex loci whose peptide products are nearly identical and act in the same biochemical system are tightly linked and show allelic associations. This is the case for three loci of the Rh system and four loci of the HLA system in humans (Hedrick et al., 1978), or for three loci of the esterases in the plant species Hordeum vulgare (Clegg et al., 1972; Brown \& Feldman, 1981).

\section{Geographical distribution of two-locus disequilibria}

In addition to the two pairs (Aap-A/Lap-A and $M r-A / D i a-A)$, several other pairs involving generally linked loci showed significant disequilibria in a number of populations (Aap-A/Acp-C, Acp-C/Lap- $A$, $A c p-C / M r-A, A c p-C / D i a-A)$. However, in contrast to the two previous pairs, rather random causes such as limited migration or drift may account for the extremely low values of $D_{\text {ST }}^{\prime 2}$ (Table 3 ). This hypothesis is also supported by the geographical distribution of the number of significant disequilibria over the natural range of $Q$. petraea. In general, populations at the edges of the range are characterized by a higher number of disequilibria, as for Norway, Turkey and Great Britain (Fig. 3). Similarly, the levels of disequilibria for the two main pairs of loci are also higher in these regions (Fig. 3). On the other hand, the amount of disequilibrium is lower in the central part of the natural distribution. It is likely that on the edges of the distribution, where sessile oak forests are fragmented, limited migration occurs among populations, which are therefore more exposed to genetic drift. 
Besides the preferential occurrence of disequilibria on the edges of the range, there is a slight longitudinal cline in the level of disequilibria for the two main pairs of loci (Aap-A/Lap-A, Mr-A/Dia-A). This is shown by the significant but low correlations between the $\Delta_{i j}$ values and longitude for the two pairs (Table 2). Feldman \& Christiansen (1975) have shown that when two large populations (at the extremes of the natural distribution for example) exchange genes through a stepping-stone model among intermediate populations, a cline will be created not only for allele frequencies but also for gametic disequilibrium. In a previous paper, on the same set of populations, Zanetto \& Kremer (1995) have shown that allozyme frequencies show longitudinal clinal variation throughout Europe, which was interpreted as the consequences of postglacial recolonization from three refugia located in southern Europe, from Spain to the Balkans. These refugia may as well be considered as the large constant populations of Feldman and Christiansen's 'finite linear stepping-stone chain of populations', that is nowadays constituted by the oak forests in Europe. Clinal variation of zygotic disequilibrium may therefore result from the recolonization patterns, as for allele frequencies (Zanetto \& Kremer, 1995).

\section{Multilocus population differentiation}

Causes of multilocus differentiation arise from three main sources: (i) the single-locus differentiation of each locus included in the multilocus combination, i.e. population differences of single-locus allele frequencies; (ii) allelic associations at different loci within populations (zygotic disequilibria, in our case); and (iii) allelic associations at different loci at the population level, i.e. correlation between allele frequencies. Our experimental results (Table 5) have shown that a significant increase of differentiation can be obtained when there is discrepancy in the correlation at the within- and between-population levels as shown earlier for quantitative traits (Kremer et al., 1996). In general, there were stronger allelic associations between two loci at the population level than at the individual level (Table 5). Allelic associations at the population level may of course result from allelic associations at the individual level. This is probably the case for the two pairs (Aap-A/Lap-A and Mr-A/Dia-A), which show high correlation both at the within- and the betweenpopulation levels (Table 5). Our data however indicate for most of the other pairs that correlations of allelic frequencies among populations do not stem only from zygotic disequilibria. If, by chance, alleles were associated differentially in the original refugia, but without any disequilibrium, then population correlation may just originate from common historical causes. If the present allele frequencies in the regions of the refugia are considered to be representative of the original refugial populations, then there were clearly different associations of alleles in Spain, Italy or the Balkans, as demonstrated by the single-locus data (Zanetto \& Kremer, 1995).

\section{Geographical multilocus patterns of diversity}

When the information from all eight loci was used in a multivariate analysis of variance, 12 per cent of the total variability could be attributed to population subdivision. This is a composite measure of differentiation that takes into account allelic associations at the zygotic level, including of course gametic disequilibrium (Kremer et al., 1996), but also allelic associations among populations. These data summarize the results previously obtained with single-locus data (Zanetto \& Kremer, 1995), and those obtained in the present study. Both emphasized the importance of the subdivision of the range of $Q$. petraea into three separated refugia during the last glaciation (Bennett et al., 1991), which have been confirmed by recent chloroplast DNA data (Ferris et al., 1993; Petit et al., 1993). The separation of the species lasted long enough so that these refugial populations became differentiated. The actual east-west pattern of nuclear diversity in sessile oak stands has largely been shaped by the postglacial recolonization pathways, resulting in clinal variation of allele frequencies and zygotic disequilibria, as predicted by theoretical models (Feldman \& Christiansen, 1975; Barbujani, 1988) and as illustrated by the geographical variation of the first canonical variate (Figs 4a, b). Furthermore, the absence of any sharp discontinuity along the longitudinal gradient suggests that the populations from the extremities of the natural range of the species have probably exchanged nuclear genes through pollen dispersion, whereas limits of seed dispersion from the original refugia were clearly delineated on the basis of chloroplast DNA data (Ferris et al., 1993; Petit et al., 1993). Finally, the important gene flow caused by pollen movement between differentiated original refugial populations has resulted in extremely low population differentiation $\left(G_{\mathrm{ST}}=2.5\right.$ per cent, Zanetto \& Kremer, 1995), but still geographically organized along a continental gradient. 


\section{Acknowledgements}

The research was supported by an ONF (Office National des Forêts) grant and by a EEC grant of DG12 (Programm FOREST no. MA2B-CT91-0022) 'Description of the genetic variation in oak populations by means of molecular markers and adaptative traits'. We thank Gregor Aas, Anna Bauer, Kornel Burg, Valeriu Enescu, Alan Fletcher, Dominique Jacques, Mustafa Kizmaz, Jochen Kleinschmit, Armin König, Hervé Le Bouler, Klaus Liepe, Sean Mac An tSaoir, Soren Madsen, Ferdinand Müller, Kórnik Pan, Tore Skrøppa, Bernd Stimm, Alexander Tucovic and the French National Forest Service (ONF) for providing the material; also Guy Roussel, Sophie Bartaire, Alexis Ducousso and Laurent Salera for their technical assistance in collecting the material and performing the electrophoretic analysis, and Rémy Petit and Martin Lascoux for critically reviewing the manuscript.

\section{References}

BACILIERl, R., DUCOUSSO, A., PETIT, R. J. AND KREMER, A. 1996. Mating system and asymmetric hybridization in a mixed stand of European oaks. Evolution, 50, 900-908.

BARBUJANI, G. 1988. Detecting and comparing the direction of gene frequency gradients. J. Genet. 67, 129-140.

BENNETT, J. H. AND BINET, F. E. 1956. Association between Mendelian factors with mixed selfing and random factors. Heredity, 10, 51-55.

BENNETT, K. D., TZEDAKIS, P. C. AND WILLIS, K. J. 1991. Quaternary refugia of the north European trees. $J$. Biogeogr., 18, 103-115.

BLACK, W. C., IV AND KRAFSUR, E. S. 1985. A Fortran program for the calculation and analysis of two-locus linkage disequilibrium coefficients. Theor. Appl. Genet., 70, 491-496.

Bousouet, J., CHEliAK, w. M. AND LALONDE, M. 1987. Allozyme variability in natural populations of green alder (Alnus crispa) in Quebec. Genome, 29, 345-352.

BROWN, A. H. D. 1975. Sample sizes required to detect linkage disequilibrium between two and three loci. Theor. Pop. Biol., 8, 184-201.

BROWN, A. H. D. AND FELdMAN, M. W. 1981. Population structure of multilocus associations. Proc. Natl. Acad. Sci., 78, 5913-5916.

BROWN, A. H. D., MATHESON, A. C. AND ELRIDGE K. G. 1975. Estimation of the mating system of Eucalyptus obliqua L'Herit. using allozyme polymorphisms. Aust. J. Bot., 23, 931-949.

CHELIAK, W. M., MORGAN, K., DANCIK, B. P., STROBECK, C. AND YEH, F. C. H. 1984. Segregation of allozymes in megagametophytes of viable seed from a natural population of Jack Pine, Pinus banksiana Lamb. Theor. Appl. Genet., 69, 145-151.
CleGG, M. T., Allard, R. W. AND KAHLER, A. L. 1972. Is the gene the unit of selection? Evidence from two experimental populations of barley. Proc. Natl. Acad. Sci., 69, 2474-2478.

COCKERHAM, C. C. AND WEIR, B. S. 1977. Digenic descent measures for finite populations. Genet. Res., 30, 121-147.

CONKLE, M. T., HODGKISS, P. D., NUNNALLY, L. AND HUNTER, S. 1982. Starch Gel Electrophoresis of Conifer Seeds: a Laboratory Manual. General technical report PSW 64. USDA Experiment Station, Washington, DC.

DIXON, M. AND WElb, E. C. 1979. Enzymes, 3rd edn. Academic Press, New York.

EPPERSON, B. K. AND ALLARD, R. W. 1987. Linkage disequilibrium between allozymes in natural populations of lodgepole pine. Genetics, 115, 341-352.

FELDMAN, M. W. AND CHRISTIANSEN, F. B. 1975. The effect of population subdivision on two loci without selection. Genet. Res., 24, 151-162.

FERRIS, C., OLIVER, R. P., DAVY, A. J. AND HEWITT, G. M. 1993. Native oak chloroplasts reveal an ancient divide across Europe. Mol. Ecol., 2, 337-344.

HASl_AM, E. 1974. The Shikimate Pathway. London Butterworths, London.

HEDRICK, P. W. 1985. Genetics of Populations. Jones and Bartlett Publishers, Boston, MA

HEDRICK, P. W., JAIN, S. AND HOLDEN, L. 1978. Multilocus systems in evolution. Evol. Biol., 11, 101-184.

KREMER, A., ZANETTO, A. AND Ducousso, A. 1996. Multilocus and multitrait measures of differentiation for gene markers and phenotypic traits. Genetics (in press).

LAURIE-AHLBERG, C. C. AND WeIR, B. s. 1979. Allozymic variation and linkage disequilibrium in some laboratory populations of Drosophila melanogaster. Genetics, 92, 1295-1314.

LONG, J. C., SMOUSE, P. E. AND WOOD, J. W. 1987. The allelic correlation structure of Gainj- and Kalam-speaking people. II. The genetic distance between population subdivisions. Genetics, 117, 273-283.

MERKLE, S. A., ADAMS, W. T. AND CAMPBELL, R. K. 1988 Multivariate analysis of allozyme variation patterns in coastal Douglas fir from southwest Oregon. Can. J. Forest Res., 18, 181-187.

MITTON, J. B. AND KOEHN, R, K. 1973. Population genetics of marine pelecypods. III. Epistasis between functionally related isoenzymes of Mytilus edulis. Genetics, 73, 27-34.

MÜLlER-STARCK, G., ZANETTO, A., KREMER, A. AND HERZOG, s. 1996. Inheritance of isozymes in sessile oak (Quercus petraea (Matt.) Liebl.) and offspring from interspecific crosses. Forest Genet., 3, 3-14.

MUONA, U, 1982. Predominantly causes for multilocus structure in predominantly outcrossing species. Silva Fenn., 16, 107-114.

NEI, M. AND LI, W.-H. 1973. Linkage disequilibrium in subdivided population. Genetics, 75, 213-219.

OHTA, T. 1982a. Linkage disequilibrium due to random genetic drift in finite subdivided populations. Proc. Natl. Acad. Sci., 79, 1940-1944.

(c) The Genetical Society of Great Britain, Heredity, 78, 476-489. 
OHTA, T. 1982b. Linkage disequilibrium with the island model. Genetics, 101, 139-155.

OTT, L. AND SCANDalios, J. G. 1978. Genetic control and linkage relationships among aminopeptidases in maize. Genetics, 89, 137-146.

PETIT, R. J., KREMER, A. AND WAGNER, D. B. 1993. Geographic structure of chloroplast DNA polymorphisms in European oaks. Theor. Appl. Genet., 87, 122-128.

ROBERDS, J. H. AND BROTSCHOL, J. V. 1985. Linkage disequilibria among allozyme loci in natural populations of Liriodendron tulipifera L. Silvae Genet., 34, 137-141.

SCANDALIOS, J. G. 1969. Genetic control of multiple molecular forms of enzymes in plants : a review. Biochem. Genet., 3, 37-79.

STRAUSS, S. H., LANDE, R. AND NAMKOONG, G. 1992. Limitations of molecular marker aided selection in forest tree breeding. Can. J. Forest Res., 22, 1050-1061.

VAllejos, C. E. 1983. Enzyme activity staining. In: Tanksley, S. D. and Orton, T. J. (eds) Enzymes in Plant Genetics and Breeding, Part A, pp. 469-516. Elsevier, Amsterdam.
WEIR, B. S. 1979. Inferences about linkage disequilibrium. Biometrics, 25, 235-254.

WEIR, B. S. 1990. Genetic Data Analysis. Sinauer Associates, Suntherland, MA.

WEIR, B. S., AND COCKERHAM, C. C. 1984 . Estimating $F$-statistics for the analysis of population structure. Evolution, 38, 1358-1370.

YANG, R. C. AND YEH, F. C. 1993. Multilocus structure in Pinus contorta Dougl. Theor. Appl. Genet., 87, 568-576.

YEH, F. C. AND MORGAN, K. 1987. Mating system and multilocus associations in a natural population of Pseudotsuga menziesii (Mirb.) Franco. Theor. Appl. Genet., 73, 799-808.

ZANETTO, A., ROUSSEL, G. AND KREMER, A. 1994. Geographic variation of interspecific differentiation between $Q$. robur $\mathrm{L}$. and Quercus petraea (Matt.) Liebl. Forest Genet., 1, 111-123.

ZANETTO, A. AND KREMER, A. 1995. Geographical structure of gene diversity in Quercus petraea (Matt.) Liebl. I. Monolocus patterns of variation. Heredity, 75, 506-517.

ZANETTO, A., KREMER, A., MÜLLER-STARCK, G. AND HATTEMER, H. H. 1996. Inheritance of isozymes in pedunculate oak (Quercus robur L.). J. Hered., 87 (in press). 